\title{
Análise de manifestações patológicas associadas a umidade em residências unifamiliares em Santo Antônio de Jesus - Bahia
}

\author{
D. Nascimento*, L. Farias², L. De Sousa ${ }^{3 *}$ \\ *Autor de Contato: 1ucarb08@gmail.com \\ ${ }^{1,3}$ Faculdade de Engenharia civil, Faculdade de Ciências e Empreendedorismo, FACEMP, Santo Antônio de Jesus, \\ Brasil \\ ${ }^{2}$ Programa de Engenharia Civil, Universidade Federal do Rio de Janeiro, Rio de Janeiro, Brasil
}

\begin{abstract}
RESUMO
As manifestações patológicas, na construção civil, evidenciadas por manchas de umidade, bolhas em pinturas, corrosão do aço e eflorescência tem relação forte com a alta umidade do ambiente. Diante desse contexto, este trabalho teve como objetivo identificar manifestações patológicas e, de forma preliminar, apresentar os processos necessários de recuperação em residências onde o solo possui nível de água alto. O estudo foi realizado por meio de um estudo de caso da rua Nestor Santos do município de Santo Antônio de Jesus - Bahia, Brasil, através de visitas técnicas, checklists e registros fotográficos das manifestações patológicas. Constatou-se que as manifestações patológicas relacionadas à umidade como umidade ascendente por capilaridade foram as mais observadas acarretando manchas, proliferação de fungos, corrosão e eflorescências. As residências foram construídas sem projeto ou execução de impermeabilização. Todos os tratamentos destes sintomas de deterioração devem ser feitos após conter a fonte de infiltração de água no componente da edificação com a correta impermeabilização.
\end{abstract}

Palavras-chave: Manifestações patológicas; construção civil; umidade; impermeabilização.

\section{ABSTRACT}


Pathological manifestations in civil construction, evidenced by damp stains, bubbles in paint, steel corrosion and efflorescence, are strongly related to the high humidity of the environment. In this context, this work aimed to identify pathological manifestations and, in a preliminary way, present the necessary recovery processes in homes where the soil has a high water level. The study was carried out through a case study of Nestor Santos street in the municipality of Santo Antônio de Jesus - Bahia, Brazil, through technical visits, checklists and photographic records of pathological manifestations. It was found that pathological manifestations related to moisture, such as rising damp by capillary action, were the most observed, causing stains, proliferation of fungi, corrosion and efflorescence. The houses were built without project or execution of waterproofing. All treatments for these deterioration symptoms must be carried out after containing the water infiltration source in the building component with the correct waterproofing.

Keywords: Pathological manifestations; construction; moisture; waterproofing.

\section{RESUMEN}

Las manifestaciones patológicas en la construcción civil, evidenciadas por manchas de humedad, burbujas en la pintura, corrosión del acero y eflorescencias, están fuertemente relacionadas con la alta humedad del ambiente. En este contexto, este trabajo tuvo como objetivo identificar las manifestaciones patológicas $\mathrm{y}$, de manera preliminar, presentar los procesos de recuperación necesarios en los hogares donde el suelo tiene un alto nivel de agua. El estudio se realizó a través de un estudio de caso de la calle Nestor Santos en la ciudad de Santo Antônio de Jesus - Bahía, Brasil, a través de visitas técnicas, listas de verificación y registros fotográficos de manifestaciones patológicas. Se encontró que las manifestaciones patológicas relacionadas con la humedad como la humedad ascendente por capilaridad fueron las más observadas, provocando manchas, proliferación de hongos, corrosión y eflorescencias. Las casas fueron construidas sin proyecto ni ejecución de impermeabilizaciones. Todos los tratamientos de estos síntomas de deterioro deben realizarse después de contener la fuente de infiltración de agua en el componente del edificio con la correcta impermeabilización.

Palabras clave: Manifestaciones patológicas; construcción civil; humedad; impermeabilización.

\section{INTRODUÇÃO}

O termo patologia, oriundo das palavras gregas pathos (doença) e logia (ciência) é empregado na engenharia civil para a ciência que investiga causas do aparecimento de fissuras, manchas, entre 
outras manifestações consideradas patológicas em uma construção (Peres, 2001). O surgimento de manifestações patológicas se deve à idade avançada das edificações ou, quando ocorre precocemente, associadas a falhas no projeto ou execução.

O estudo das manifestações patológicas é complexo pois estão envolvidos vários fatores, entre os quais pode-se citar: erros no projeto, falha na execução, ausência de manutenção preventiva, material de baixa qualidade ou dosado incorretamente, não considerar a agressividade do meio ambiente (Santos, 2010). Dentre estes fatores, a falta de impermeabilização é agravante para o desempenho da edificação, pois, sem a qual, ficam expostos à água elementos tais como vigas baldrames, paredes, pisos de ambientes molhados, vazamento de água pluvial por calhas de drenagem ou pelo telhado na cobertura, acúmulo de água nos peitoris das janelas e no topo de muros por falta de caimento (Segat, 2005).

O processo de impermeabilização envolve o uso de materiais impermeabilizantes e atenção aos padrões normativos de projeto NBR 9575 (Associação Brasileira de Normas Técnicas, 2010) e execução NBR 9574 (Associação Brasileira de Normas Técnicas, 2008). Sempre se faz necessário a mão de obra especializada aliado a um projeto eficiente para que se evite problemas advindos da água infiltrada (Bezerra, 2013).

Segundo Souza e Ripper (2009) na concepção do projeto é fundamental evitar problemas construtivos e procurar soluções técnicas otimizadas visando a segurança, servicibilidade e vida útil da construção. No entanto, é notório a inexistência do projeto de impermeabilização especialmente em construções de pequeno porte, que, em geral, não são assistidas do Engenheiro Civil, Arquiteto ou algum profissional capacitado tecnicamente (Hussein, 2013; Vieira e Barreiros, 2019; Fronza, 2019). A maioria destas construções são, então, passíveis de ter desempenho reduzido após a entrega da obra.

A água tem capacidade de absorver substâncias e transportar íons, logo pode potencializar a corrosão do aço e o surgimento de fissuras ou a desagregação em concreto armado, levando ao aumento do risco de ruptura ou limitações de uso estrutural. Ademais, afirma Suplicy (2012) que quando a água permeia o material cimentício, sucede o aumento de porosidade com o tempo, provocado pela dissolução dos compostos microestruturas e fissuras resultantes da precipitação de compostos expansivos. Então, a permeabilidade de agentes agressivos é facilitada e o material cimentício é deteriorado mais cedo.

A lixiviação, devido ao fluxo de água pelo material cimentício, de compostos químicos hidratados do cimento como o hidróxido de cálcio $[\mathrm{Ca}(\mathrm{OH}) 2]$ pode resultar em manchas superficiais de cor esbranquiçada e aumento de porosidade do concreto (Metha e Monteiro, 2017). Relata-se ainda surgimento de mofo, empolamento nas pinturas, desagregação da argamassa que prejudicam estaticamente a edificação (IBI Brasil, 2018, Brasil, 2014). O mofo, acúmulo de bactérias e fungos tornam o local frio e prejudicial à saúde humana (Suplicy, 2012).

Estes problemas não se restringem, no entanto, a países em desenvolvimento, pois países como a Noruega estudos relatam que problemas relacionados com a água somam $76 \%$ das patologias de edificações (Freitas, 2013). De acordo com a Organização Mundial de Saúde (OMS, 2009) cerca de $75 \%$ a $80 \%$ das manifestações patológicas surgem no revestimento de uma edificação tem suas origens na umidade. Neste contexto, a presença contínua da água nas edificações é problemática na durabilidade e evidencia-se a importância da impermeabilização.

Uma falha recorrente em construções de pequeno porte consiste ausência da impermeabilização de baldrames (fundação em contato com o solo). Isto permite que a umidade ascendente do solo passe pelos elementos da fundação, alcançando até 1 metro de altura em paredes com revestimento de argamassa devido a forças capilares (Cichinelli, 2012).

Algumas soluções para problemas de água ascendente por capilaridade são ineficazes, em caso de paredes com pintura refeita, no futuro será necessário nova intervenção, pois a umidade causará mesmo problema. Em outra situação, pode-se aplicar o revestimento cerâmico para esconder o 
problema, no entanto, a umidade pode atingir maiores alturas, ainda causar um ambiente úmido e desconfortável aos moradores.

De acordo com Marques (2005) a fonte de infiltração da água no componente da edificação deve ser inibida antes de qualquer reparo. Embora existam diversas soluções e produtos de impermeabilização, ainda existem falhas ou mesmo inexistência de projetos de impermeabilização em edificações de pequeno porte ou profissionais pouco qualificados para este serviço. Visto isto, este trabalho se propõe a analisar manifestações patológicas em residências que foram construídas sem acompanhamento técnico em ambientes com nível de água em camadas superficiais do solo. Além disso, também pretende apresentar, de forma preliminar, os processos previstos para recuperação.

\section{METODOLOGIA}

Para o estudo foi escolhida a Rua Nestor Santos do município de Santo Antônio de Jesus (Bahia, Brasil) com tipologias de construções similares (estruturas de concreto armado, alvenaria de blocos cerâmicos, revestimento com argamassa, construções de pequeno porte de até 2 pavimentos). As residências foram construídas sem um acompanhamento técnico. A rua possui perímetro de 376,21 metros e área de $3.662,38 \mathrm{~m}^{2}$, e coordenadas geográficas $12^{\circ} 58^{\prime} 07^{\prime \prime} \mathrm{S}$, e $39^{\circ} 15^{\prime} 54^{\prime \prime W}$ (Figura 01). A pesquisa foi realizada de forma sistemática em 17 residências. Esta rua foi escolhida pois há nível de água superficial do solo, sendo quem em proximidades há uma fonte de água. Todas as residências foram autoconstruídas, ou seja, conforme o conhecimento técnico do proprietário e da mão de obra executante, sem acompanhamento de profissionais tais como engenheiro ou arquiteto.

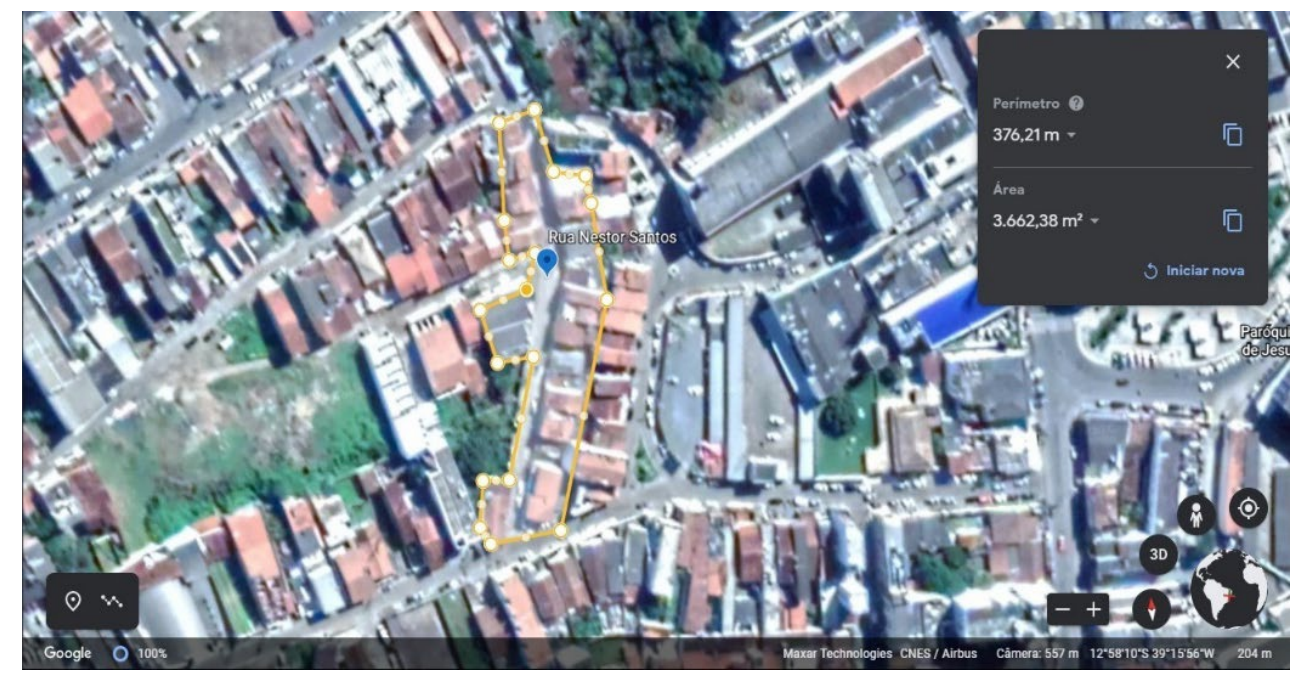

Figura 1. Delimitação da rua estudada.

Fonte: Google Earth, 2020.

$\mathrm{Na}$ visita às edificações foi feito um levantamento de manifestações patológicas conforme o cheklist do Tabela 1, este foi baseado em trabalhos que investigaram manifestações patológicas causadas por umidade ascendente (Viera e Barretos, 2019; Hussein, 2013). Para a coleta de dados, tendo como princípio o estudo da umidade ascendente do solo, limitou-se ao pavimento térreo das residências em paredes que não possuiam instalações hidráulicas ou sanitárias.

Tabela 1. Checklist com manifestações observáveis nas residências. 


\begin{tabular}{|l|l|}
\hline Identificação de manifestações patológicas na residência. \\
\hline ( ) Fissuras/Trincas & ( ) Bolhas em pinturas \\
\hline ( ) Mofos & ( ) Descolamento de piso/azulejo \\
\hline ( ) Corrosão de armadura & ( ) Umidade ascendente por capilaridade \\
\hline ( ) Outros & \\
\hline
\end{tabular}

Foram realizados registros fotográficos para identificar as manifestações patológicas no interior das residências, sendo expostas no presente trabalho aquelas que foram considerados pelos autores como mais representativos em relação às manifestações patológicas elencadas no checklist.

Ressalta-se que por se tratar de análise em residências de terceiros com limitações de acesso, não foram realizadas medições e avaliações, portanto as fissuras ou trincas foram identificadas somente quando estavam presentes em elementos estruturais. A corrosão da armadura somente foi constatada quando observado o destacamento do concreto de cobrimento e identificação visual de comprometimento da seção transversal das barras de aço.

\section{RESULTADOS}

\subsection{Estudo exploratório sobre manifestações patológicas na região de estudos}

A Figura 2 detalha quantitativamente as manifestações patológicas observadas nas residências em diferentes classificações (trincas, mofos, bolhas, descolamento de cerâmica, corrosão de armadura, ascenção de água por capilaridade e outros).

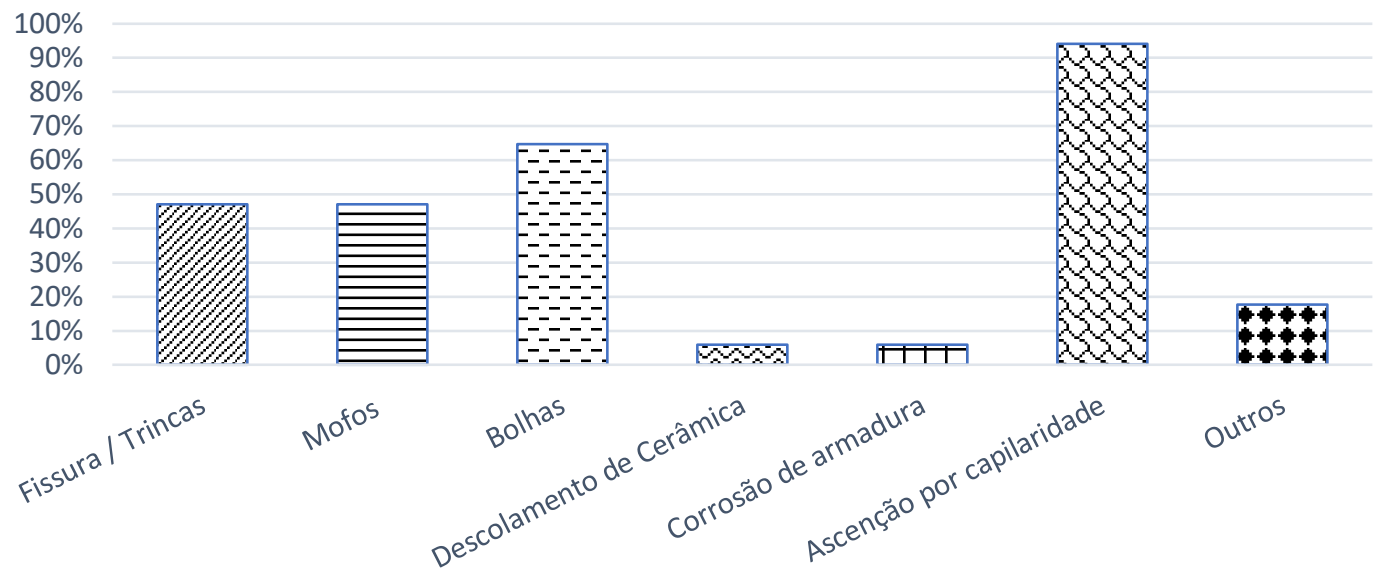

Figura 2. Tipos de manifestações patológicas observadas nas residências.

Ao longo das visitas para coleta de dados os proprietários informaram não ter sido realizado procedimentos de impermeabilização nas vigas baldrames. Percebe-se que entre as manifestações patológicas, na Figura 7, se observa a alta recorrência nas residências da umidade ascendente por capilaridade nas alvenarias que está relacionada diretamente a ação da água oriunda especialmente do solo transportada pelos poros do material cimentício, agravado pela água de chuva. Isto se deve ao fato de que as manifestações foram observadas em paredes que não possuem instalações hidráulicas ou sanitárias próximas.

Os mofos e bolhas nas pinturas são efeitos diretos da água em alvenarias, algumas machas observadas em paredes em altura próximos ao forro foram causadas pela incidência de chuvas, sendo verificado que a impermeabilização externa não foi efetuada corretamente constatada pela ausência de pintura no lado externo da alvenaria ou desgaste na mesma. As fissuras ou trincas são 
bastante recorrentes, muitas vezes atreladas à corrosão de armaduras podem ser potencializadas pela umidade ou por falhas no projeto e execução das estruturas.

\subsection{Estimativa das causas e propostas de soluções para as manifestações patológicas observadas.}

A umidade por capilaridade (Figura 3) surge através da água presente no solo úmido que percorre os elementos porosos da fundação de concreto, ascendendo à alvenaria por forças capilares. Tal fenômeno ocorre quando não há uma barreira, ou seja, uma película asfáltica ou uma manta asfáltica que reveste as vigas baldrames impossibilitando que a umidade ascenda pelas paredes.

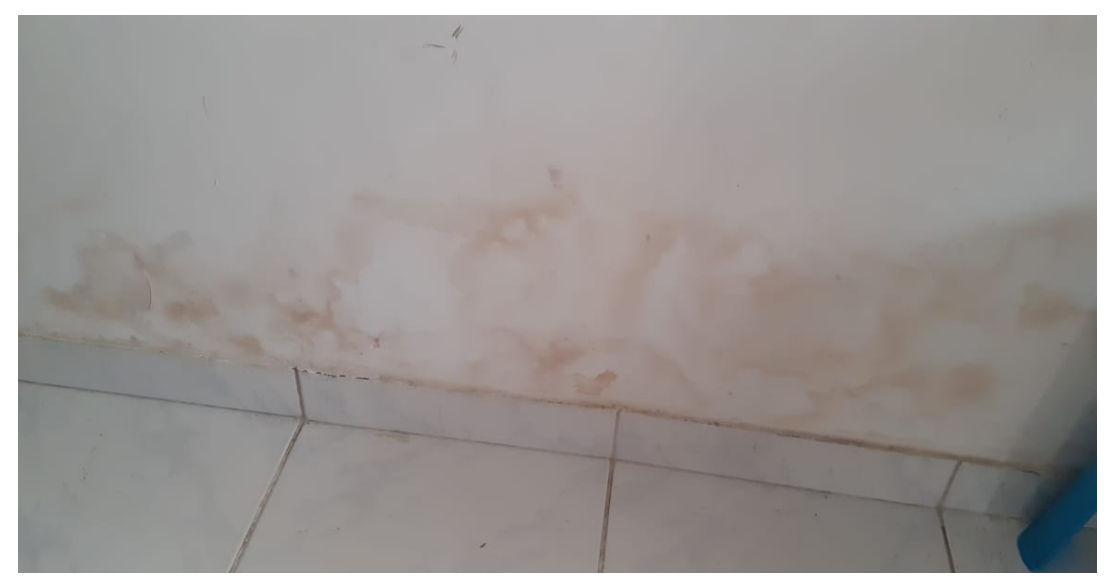

Figura 3. Manchas causadas pela ascensão de água por capilaridade.

Tal qual aponta Rangel (2014), os materiais porosos como concreto, tijolos e argamassas permitem a circulação de água por fenômenos de pressão e diferença de concentração. No primeiro caso, por pressão hidrostática, a água percola os poros em qualquer direção devido à forte pressão. No segundo, por diferença de concentração da água, a exemplo quando a água é presente superficialmente no solo, nesta situação ascende pelos poros alcançando altura, em geral, até 1 metro em alvenarias. A altura em que a umidade de capilaridade pode chegar depende da forma dos poros capilares, do diâmetro e da "limpeza", ou seja, sem preenchimento por resíduos ou outras substâncias.

A Tabela 2 mostra um procedimento terapêutico para o tipo de patologia, incluindo a identificação do local do problema, aberturas na alvenaria para aplicação de um impermeabilizante na viga baldrame e na base das primeira fiadas da alvenaria utilizar argamassa polimérica (produto que confere menor porosidade), impendido assim o fluxo de água ascendente.

Segundo Juliani (2015), como prevenção, tem-se a impermeabilização das vigas baldrames em contato com o solo. De início deve-se limpar a superfície da viga e a remoção do revestimento das três primeiras fiadas da parede; deve-se aplicar pintura asfáltica na viga e descer lateralmente no mínimo $15 \mathrm{~cm}$ (se necessário retirar parte do solo em contato); e após estar seco, aplicar argamassa impermeabilizante na viga e até as três primeiras fiadas da alvenaria.

Tabela 2. Levantamentos realizados para a patologia da Figura 3.

Descrição por inspeção visual

Manchas, descolamento de película, desagregação do reboco 


\begin{tabular}{|l|l|}
\hline Possível Causa & $\begin{array}{l}\text { Inexistência de impermeabilização das fundações e das } \\
\text { vigas baldrames }\end{array}$ \\
\hline Diagnóstico & Ascensão de água por capilaridade \\
\hline Terapia & 1- Identificação do local com problema; \\
& 2- Remoção do reboco e se possível da alvenaria afetada; \\
& 3- Escoramento do local, onde foi removido a alvenaria; \\
& 4 - Aplicação do impermeabilizante na viga baldrame; \\
& 5 - Vedação do local com alvenaria; \\
& 6 - Impermeabilização com argamassa polimérica nas 3 \\
& primeiras fiadas e acabamento; \\
& 7 - Aplicação de argamassa e película; \\
& 8- Realização de manutenções periódicas. \\
\hline
\end{tabular}

Além do acabamento estético que confere a pintura, esta passa a ser um elemento indispensável na edificação para proteger os elementos construtivos e aumentar a durabilidade da construção. Isto porque, segundo Deutsch (2011) as tintas e massa corrida são utilizados para proteção e acabamento de superfícies são formados por composições líquidas ou pastosas capazes de formar películas após a secagem ou cura.

Após a secagem podem surgir bolhas na pintura isto indica que a alvenaria de vedação está sujeita à umidade ascendente ou infiltração, quando a umidade chega até o substrato ela impulsiona a película da pintura formando as bolhas, como apresenta a Figura 4.

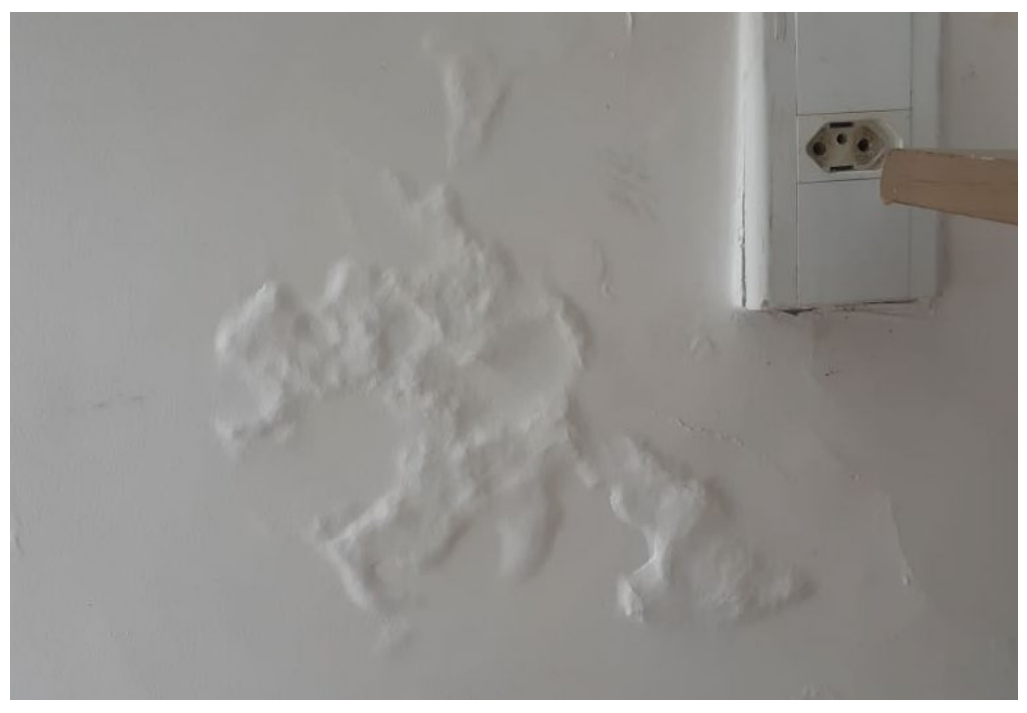

Figura 4. Formação de bolhas na pintura de acabamento.

Na Tabela 3 mostra a terapêutica para resolver problemas de bolhas em pinturas, no entanto, deve ser feito antes o reparo da infiltração ou inibir a umidade ascendente.

Tabela 3. Levantamentos realizados para a patologia da Figura 4.

\begin{tabular}{|l|l|}
\hline Descrição por inspeção visual & Deslocamento da película de tinta devido a umidade \\
\hline Possível Causa & Inexistência de impermeabilização ou infiltração \\
\hline
\end{tabular}




\begin{tabular}{|l|l|}
\hline Diagnóstico & Bolhas na pintura \\
\hline Terapia & 1 - Remoção das bolhas com espátula de aço; \\
& 2-Aplicação de um fundo preparador a base d'água; \\
& 3-Aplicação de massa corrida; \\
& 4- Lixar toda a parede; \\
& 5-Aplicação da pintura. (Silva et al. 2011). \\
\hline
\end{tabular}

A Figura 5 expõe um ambiente com bolor que é uma manifestação patológica comum em ambientes úmidos devido à falta de circulação de ar ou umidade excessiva no ambiente.

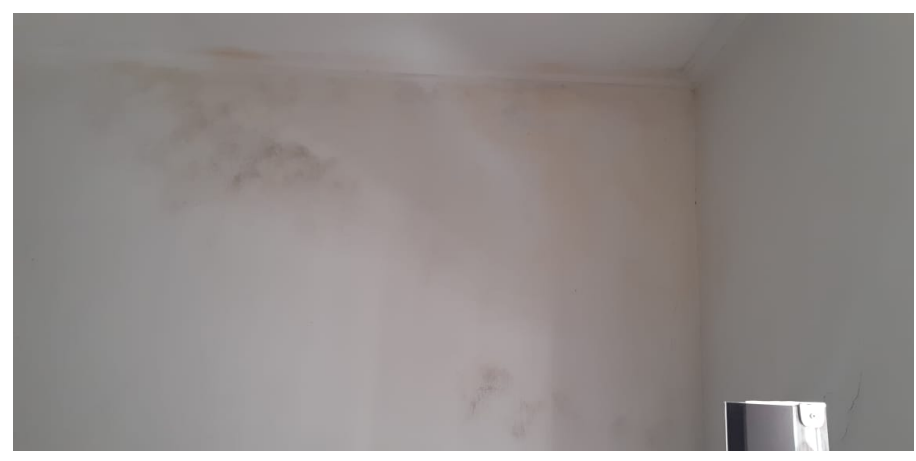

Figura 5. Surgimento de bolor em ambientes internos.

Hussein (2013) descreve que o bolor tende a prolifera-se facilmente em paredes atingidas por umidade, agravadas ainda quando não há incidência de luz solar. Portanto, a presença desta manifestação patológica indica excesso de umidade no ar, devido ao clima, ainda podem ser por umidade ascendente do solo por falta de impermeabilização ou quando feita incorretamente ou por ausência de projetos acompanhados por profissionais com conhecimento técnico. O bolor pode ser corrigido conforme mostra o Tabela 4.

Tabela 4. Levantamentos realizados para patologia da Figura 5.

\begin{tabular}{|l|l|}
\hline Descrição por inspeção visual & Bolor na alvenaria \\
\hline Possível Causa & Infiltração e falha na aplicação do reboco \\
\hline Diagnóstico & Infiltração \\
\hline Terapia & 1 - Identificação do local com problema; \\
& 2 - Limpeza do local afetado; \\
& 3 - Impermeabilização com argamassa polimérica e \\
& acabamento pelo lado onde surge a infiltração; \\
& 4 - Limpeza do local com Bolor e pintura; \\
& 5 - Realização de manutenções periódicas. \\
\hline
\end{tabular}

Na NBR 7200 (Associação Brasileira de Normas Técnicas, 1998) consta que para remover bolor e fungos: pode-se escovar a superfície com escova de cerdas duras com solução de fosfato trissódico (30 $\mathrm{g} \mathrm{Na}_{3} \mathrm{PO}_{4}$ em $1 \mathrm{~L}$ de água) ou com solução de hipoclorito de sódio (4\% a 6\% de cloro ativo) e enxaguar com água limpa em abundância. 
Nas residências também foi percebido a manifestação patológica fotografada e exposta na Figura 6. Nota-se em uma parte com o acabamento em massa corrida e pintura deteriorados e com a presença de sais de eflorescência.

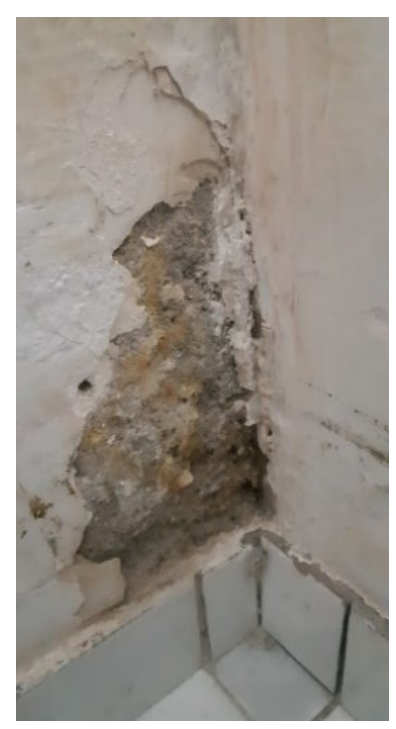

Figura 6. Eflorescência (depósitos de sais).

Segundo Sales e Silva (2013) as eflorescências são formações de sais precipitados na superfície da parede. Isto acontece devido ao fenômeno de lixiviação de compostos do cimento hidratado (Especialmente o hidróxido de cálcio $[\mathrm{Ca}(\mathrm{OH}) 2]$ pela água dos poros, por diferença de concentração ou percentual de umidade, em faces opostas do concreto ou da argamassa de revestimento.

De acordo com Suplicy (2012) acrescenta que a água percola os poros em um material componente da parede (tijolos, blocos, no cimento, na areia, no concreto e na argamassa) que contenha sais solúveis como metais alcalinos (sódio e potássio) e alcalinos terrosos (cálcio e magnésio) podem resultar em compostos químicos tais como o Carbonato de Cálcio (CaCO3) e Carbonato de Magnésio (MgCO3). Assim, dissolvendo-se na água eles percorrem até a superfície, onde a água evapora e os sais se cristalizam e se instalam na superfície, conforme apresentado na Figura 6.

Conforme a NBR 7200 (Associação Brasileira de Normas Técnicas, 1998), para remover eflorescências pode-se escovar a seco a superfície com escova de cerdas de aço e proceder a limpeza com solução de ácido muriático. Caso a manifestação atinja grandes áreas, pode-se ainda empregar jateamento.

$\mathrm{Na}$ Tabela 05 mostra um passo a passo para corrigir o problema da eflorescência sendo necessário corrigir o problema de infiltração ou percolação de umidade.

Tabela 5. Levantamentos realizados para patologia da Figura 6.

Descrição por inspeção visual $\quad$ Desagregação da argamassa e depósitos de sais 


\begin{tabular}{|l|l|}
\hline Possível Causa & Umidade \\
\hline Diagnóstico & Percolação de umidade e depósitos de sais na argamassa \\
\hline Terapia & 1 - Limpeza do local afetado com ácido muriático; \\
& 2 - Aplicação de uma nova camada de revestimento com \\
& argamassa polimérica; \\
& 3 -Aplicação de massa corrida e película de pintura para \\
& acabamento; \\
& 4 - Realização de manutenções periódicas. \\
\hline
\end{tabular}

Durante a pesquisa foi observado uma fundação sendo construída no local de estudo conforme mostra a Figura 7.

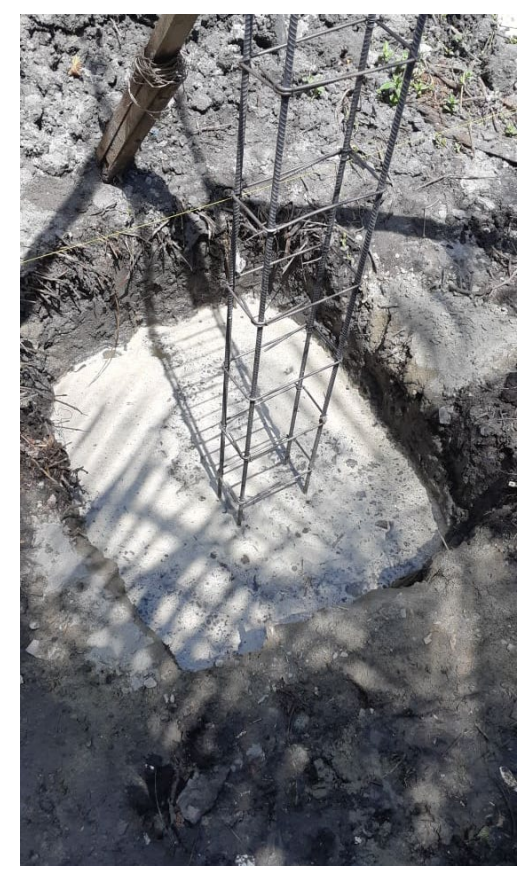

Figura 7. Nível de água alto.

Na Figura 7 foi observado o nível de água em camadas superficiais do solo, observou-se a presença de água foi "compensada" com o acrescimento de cimento, sem outros cuidados com impermeabilização ou aprofundamento do nível de água. O solo do local, segundo a análise tátilvisual tem coloração escura, provavelmente, por causa da matéria orgânica, com granulometria fina similar ao solo argiloso e a umidade, similar a um ambiente de mangue.

A observação feita na Figura 7 tem importância para entender a origem das manifestações observadas, visto que a cultura de construção no local é similar, sem acompanhamento de profissionais técnicos como engenheiros ou arquitetos. Isto mostra que além do profissional responsável pela execução não conhecer os procedimentos teóricos de técnicas construtivas, também os proprietários não estão conscientes dos problemas futuros oriundos da falta de impermeabilização ou drenagem da água subterrânea na fundação e demais componentes da edificação.

A Figura 8 a) mostra uma fissura em um local próximo à área de fixação do portão, onde provavelmente há um pilar. O contato com diferentes metais (metal do portão e o aço da armadura) também pode resultar em corrosão (Pannoni, 2007). A fissura pode ser causada por corrosão da armadura em que a expansão provoca tensões internas no concreto, provocando a desagregação do 
concreto. Na Figura 8 b) em que se nota a armadura aparente em processo de corrosão, o concreto desagregado e o aspecto de armadura exposta enferrujada.

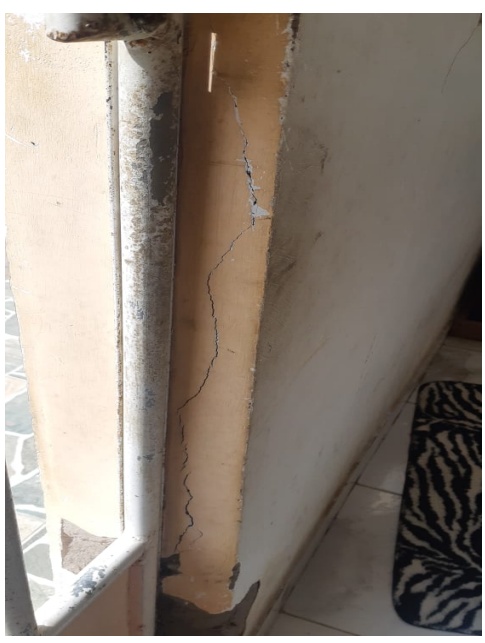

(a)

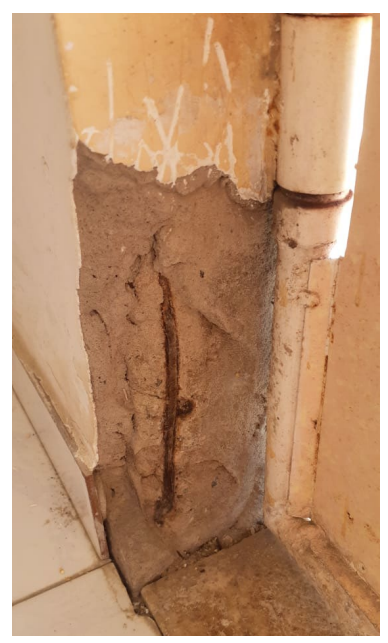

(b)

Figura 8. Fissura devido à expansão da armadura (a) e armadura exposta em processo de corrosão (b).

Segundo Marcelli (2007), a corrosão da armadura pode gerar trincas no concreto devido ao aumento de volume do aço em até oito vezes na parte afetada. A corrosão é um fenômeno de natureza eletroquímica, quando o aço tem contato com a água, o processo de corrosão é acelerado pela presença de íons e oxigênio, estabelecimento de uma célula de corrosão eletroquímica (Marcelli, 2007).

Marcelli (2007) relata ainda que as fissuras em concreto podem ocorrer devido: a corrosão, as falhas na execução; concreto com dosagem incorreta ou materiais de baixa qualidade ou contaminados; agressividade do ambiente; cobrimento da armadura insuficiente; inadequada manutenção; gradiente térmico e ação de íons cloreto.

A Tabela 6 expõe o procedimento realizado para corrigir pilares com corrosão de armadura, notase que como pilares são elementos de sustentação da construção deve-se utilizar o escoramento adequado antes de qualquer intervenção.

Tabela 6. Levantamentos realizados para patologia da Figura 8.

\begin{tabular}{|l|l|}
\hline Descrição por inspeção visual & Fissura vertical no pilar \\
\hline Possível Causa & Corrosão e expansão da armadura \\
\hline Diagnóstico & Corrosão da armadura \\
\hline Terapia & 1 - Realizar o escoramento; \\
& 2- Retirar o reboco, concreto deteriorado e limpeza; \\
& 3 - Utilizar escova de aço para retirar possível ferrugem das \\
& armaduras; \\
& $4-$ Aplicação de anticorrosivo; \\
& 5 - Em caso da armadura está em estágio avançado de \\
& corrosão, a armadura antiga será revestida com uma \\
& armadura nova; \\
& 6 - Aplicação da forma e lançamento do graute; \\
& $7-$ Aplicação de revestimento e acabamento. \\
\hline
\end{tabular}




\section{CONCLUSÕES}

O levantamento de dados das manifestações patológicas nas residências unifamiliares da Rua Nestor Santos do municipio de Santo Antônio de Jesus (Bahia, Brasil) mostrou problemas provocados por ascensão de água por capilaridade, trincas, rachaduras, manchas, desagregação do revestimento, corrosão de armaduras e eflorescência. Foi possível notar que o nível de água nesta localidade é alto e aliado a ausência de impermeabilização são os principais motivos das manifestações observadas.

Algumas destas patologías, como o mofo, podem ser inclusive prejudiciais à saúde humana, bem como a umidade pode causar queda de temperatura, mal-estar e doenças nos moradores. Isto alerta da importância da intervenção correta sobre estes problemas. Após a realização desta pesquisa, entende-se que os moradores das edificações ainda não estão conscientes sobre as causas do surgimento das manifestações patológicas, bem como desconhecem a relevância de técnicas de impermeabilização para solucioná-las.

Com isso são necessárias medidas para conscientizar a população da importância de impermeabilização e de medidas corretivas adequadas para garantir a durabilidade da edificação e o bem-estar dos moradores. Além disso, é notória a necessidade de treinamento de profissionais ou a criação de empresas de reformas para restabelecer eficientemente a condição de bom desempenho da edificação, realizando a impermeabilização necessária. .

\section{AGRADECIMENTOS}

Os autores agradecem a Faculdade de Ciências e Empreendedorismo pelo apoio e incentivo fornecido ao desenvolvimento do presente trabalho.

\section{REFERÊNCIAS}

Associação Brasileira de Normas Técnicas (1998). NBR 7200: Execução de revestimento de paredes e tetos em argamassas inorgânicas; procedimentos, Rio de Janeiro.

Associação Brasileira de Normas Técnicas. (2010). NBR 9575: Impermeabilização - Seleção e projeto, Rio de Janeiro.

Associação Brasileira de Normas Técnicas. (2008). NBR 9574: Execução de impermeabilização, Rio de Janeiro.

Barreiros, J. V. e Vieira, B. V. (2019). "Patologias em residências unifamiliares associadas à falta ou falha de impermeabilização: estudo de casos”. Engenharia Civil, Pedra Branca.

Bezerra, G. M. (2013). "Estudo da influência do arisco na formação do salitre em argamassas na região de Mossoró-RN”. Monografia (Engenharia Civil) - Universidade Federal Rural do Semiárido, Mossoró, Rio Grande do Norte, p. 42.

Cichinelli, G. (2012). “Estanqueidade garantida”. 189, Revista Téchne, São Paulo. Disponível em: <http://techne17.pini.com.br/engenharia-civil/189/artigo288006-2.aspx>. Acesso em: 08 Ago 2020. 
Deutsch, S. F. (2011). "Perícias de engenharia: a apuração dos fatos”. Leud, São Paulo. Freitas, V. P. de. (2013). “A State-of-the-Art Report on Building Pathology”. CIB-W086, Building Pathology, Portugal.

Fronza, M. P. (2020). "Análise e tratamento de patologias causadas pela umidade em edificações residenciais térreas, devido à falha ou ausência de impermeabilização”. 2020.

Helene, P. R.L. (1986). “Corrosão em armadura para concreto armado”. 1. ed. Pini, São Paulo.

Hussein, J. S. M. "Levantamento de patologias causadas por infiltrações devido à falha ou ausência de impermeabilização em construções residenciais na cidade de Campo Mourão - PR". 2013. 54f. Dissertação de Mestrado em Engenharia Civil, Universidade Tecnológica Federal do Paraná, Campo Mourão, 2013.

IBI Brasil. (2018). Guia de aplicação da norma de desempenho para impermeabilização: especificação, aplicação e contratação com foco no atendimento à ABNT NBR 15575:2013. IBI Brasil (Instituto de Impermeabilização), São Paulo, p. 7.

Juliani, M. A. (2015). "Análise de manifestações patológicas em condomínio construído com alvenaria estrutural: estudo de caso”. Trabalho de Conclusão de Curso. Graduação em Engenharia Civil - Universidade Federal de Santa Catarina, Florianópolis, SC, p. 119.

Marcelli, M. (2007). "Sinistros na construção civil: Causas e soluções para danos e prejuízos em obras". Pini, São Paulo, p. 270.

Marques, R. (2005). “Proteção Subterrânea”. 96, Téchne, São Paulo, p. 49.

Mehta, P. K e Monteiro, P. J. M. (2017) “Concrete microstructure, properties and materials”. McGraw-Hill.

Organização Mundial da Saúde (OMS). (2009). "WHO guidelines for indoor air quality: dampness and mould". Copenhagen, Denmark.

Pannoni, D. F. (2007). “Fundamentos da corrosão”. Pintura industrial, 48 (16), p. 32-35.

Peres, R. M. "Levantamento e identificação de manifestações patológicas em prédio histórico um estudo de caso". Dissertação de mestrado em Engenharia Civil. Programa de Pós-Graduação em Engenharia Civil. Universidade Federal do Rio Grande do Sul, Porto Alegre, 2001.

Rangel, L. (2014). “Impermeabilização é o ponto de partida”. Revista Condomínio, 63, p. 8.

Sales, J. C. e Silva, I. S. (2013). "Patologias ocasionadas pela umidade: estudo de caso em edificações da Universidade Estadual Vale do Acarau - UVA”. IX Congresso Internacional sobre Patología y Recuparación de Estructuras. Cinpar 2013.

Santos, T. C. S. (2010). "Plano de ação voltado a manutenção de sistemas de pintura em escolas públicas”. UFPR, Londrina.

SEGAT, G. T. (2005). "Manifestações patológicas observadas em revestimentos de argamassa: Estudo de caso em conjunto habitacional popular na cidade de Caxias do Sul (RS)". Tese 
(Doutorado) - Curso de Engenharia Civil, Universidade Federal do Rio Grande do Sul, Porto Alegre, p. 166.

Silva, D. J. e Lopes, P. (2011). "Relatório de Vistoria de Patologias Prediais”. Florianópolis, disponível em: <http://dfo.ufsc.br/files/2011/10/RELATORIO_CCB_J_V8.pdf >. Acesso em 03 de Maio de 2021.

Souza, V. e Ripper, T. (2009). "Patologia, recuperação e reforço de estruturas de concreto”. PINI, São Paulo.

Suplicy, G. F. S. (2012). "Patologias ocasionadas pela umidade nas edificações”. Trabalho de conclusão de curso apresentado ao Programa de Pós-Graduação Lato Sensu da Escola de Engenharia da Universidade Presbiteriana Mackenzie, São Paulo. 